CORRÊA, M. (1999), "O sexo da dominação". Novos Estudos Cebrap, 54: 43-53.

DAVIDA (GRUPO). (2005), "Prostitutas, 'traficadas' e pânicos morais: uma análise da produção de fatos em pesquisas sobre o 'tráfico de seres humanos". Cadernos Pagu, 25: 153-184.

DWORKIN, G. (1998 2008), The theory and practice of autonomy. Nova York, Cambridge University Press.

FARIA, N. (2014). "A quem serve a regulamentação da prostituição?”. Disponível em http:// br.boell.org/pt-br/2014/05/10/quem-serve-regulamentacao-da-prostituicao, consultado em 30 jun. 2014.

MACKENZIE, C. \& STOLJAR, N. (2000), "Autonomy refigured", in C. Mackenzie e N. Stoljar (eds.), Relational autonomy: feminist perspectives on autonomy, agency, and the social self, Nova York/Oxford, Oxford University Press.

MARQUES, D. \& MONTEZUMA, I. (2014), "Desigualdades de gênero e democracia: como as ciências sociais brasileiras (não) trabalham com o tema". Trabalho apresentado no $38^{\circ}$ Encontro Anual da Anpocs, Caxambu.

MOI, T. (1991), "Appropriating Bourdieu”. New Literary History, 22: 1017-1049.

PISCITELLI, A. (2012), "Revisiting notions of sex trafficking and victims". Vibrant, 9: 275-310.

YOUNG, I. (2011), Responsibility for justice. Oxford, Oxford University Press.

JOSÉ SZWAKO é professor do Instituto de Estudos Sociais e Políticos da Universidade do Estado do Rio de Janeiro (Iesp-Uerj). E-mail: zeszwako@iesp.uerj.br.

DOI: http//dx.doi.org/10.17666/3089182-186/2015

\section{Por uma teoria alternativa do campesinato nas fronteiras do capitalismo}

Francisco de Assis Costa. Economia camponesa nas fronteiras do capitalismo: teoria e prática nos EUA e na Amazônia brasileira. Belém, Naea/UFPA, 2012. 310 páginas.

\section{Luiz Cláudio Moreira Melo Jr.}

Francisco de Assis Costa (nascido em 1948) é professor do Núcleo de Altos Estudos Amazônicos da Universidade Federal do Pará (Naea/UFPA) desde 1989. Doutorou-se em 1988 em economia pela Freie Universität Berlin, Alemanha. Coordena o grupo de pesquisa Dinâmica Agrária e Desenvolvimento Sustentável na Amazônia, que há anos vem desenvolvendo estudos que compõem uma ampla abordagem interdisciplinar da Amazônia. É autor de diversas obras de referência sobre dinâmica agrária e campesinato na Amazônia, entre elas: Ecologismo e questão agrária na Amazônia (Naea/UFPA, 1992), Grande capital e agricultura na Amazônia: a experiência Ford no Tapajós (Naea/UFPA, 1993) e Formação agropecuária da Amazônia: os desafios do desenvolvimento sustentável (Naea/UFPA, 2000). Recentemente, a produção do seu grupo de pesquisa tem sido organizada e divulgada em cinco séries temáticas, contando com o lançamento de títulos inéditos, como é o caso da obra aqui resenhada, além de reedições de obras anteriores. A obra Economia camponesa nas fronteiras do capitalismo é o volume 1 da série II, denominada Fundamentos Teóricos e Metodológicos.

Eu sintetizaria assim a temática desse novo livro de Francisco de Assis Costa: trata-se da construção das bases teórico-metodológicas da teoria do investimento camponês como uma proposta alternativa ao entendimento do campesinato nas fronteiras do capitalismo. A teoria é defendida tanto para a fronteira mais intensiva do sistema (campesinato americano), como para a sua fronteira mais extensiva (campesinato amazônico), mostrando a eficiência reprodutiva e a capacidade de permanência da economia em bases camponesas.

$\mathrm{O}$ autor fundamenta as suas análises utilizando dados secundários dos Censos dos Estados Unidos 
e do Brasil e dados primários como resultados de décadas de pesquisas sobre sociedades camponesas na região amazônica brasileira. Apresenta ainda alguns modelos matemáticos e exemplos numéricos. Destaco a consistência e a densidade teórica e metodológica da obra, que dialoga com diferentes tradiçôes de estudos sobre campesinato, como a marxista, a neoclássica, a chayanoviana, e os seus desdobramentos nas ciências sociais brasileiras em autores como José Eli da Veiga, José de Souza Martins, José Graziano da Silva, Maria Wanderley, Octávio Ianni, Otávio Velho e Ricardo Abramovay, como destacarei no decorrer desta resenha.

O livro, ao longo dos seus doze capítulos, aborda três teses principais: i) a não separação entre as esferas da produção e do consumo como uma especificidade das estruturas sociais camponesas; ii) a eficiência reprodutiva, a mobilização ao investimento e a capacidade de permanência como características importantes do campesinato nas fronteiras do capitalismo; e iii) a centralidade do elemento camponês ou da realidade camponesa para a compreensão do contexto agrário amazônico.

Quanto ao primeiro ponto, vale destacar que o autor entende como camponesas "aquelas famílias que, tendo acesso à terra e aos recursos naturais que ela suporta, resolvem seus problemas reprodutivos a partir da produção rural - extrativa, agrícola e não agrícola - desenvolvida de tal modo que não se diferencia o universo dos que decidem sobre a alocação do trabalho, dos que sobrevivem com o resultado dessa alocação" (pp. 117-118). Tal definição herda do economista russo Alexander von Chayanov a ênfase na centralidade das necessidades reprodutivas da família no processo decisório da "empresa camponesa", constituindo, assim, uma unidade indissociável entre as esferas da produção e do consumo. Trata-se de uma lógica de produção que se orienta não por critérios de eficiência do capital, mas por critérios de eficiência reprodutiva da família enquanto unidade de produção, diferentemente do que ocorre em estruturas capitalistas.

Assumir de forma integral essa perspectiva implica assumir, também integralmente, as suas consequências lógicas e teóricas, a saber: a) a unidade camponesa tende a ser regulada em seu tamanho e em sua capacidade de mudar pela potência de tra- balho que possui enquanto família; e b) as forças que emergem das tensôes contrárias, originadas, por um lado, das necessidades reprodutivas e, por outro, das tensões ligadas ao próprio exercício do trabalho, estabelecem um hábito de consumo ajustado a uma rotina de trabalho entendida como adequada. Tal discussão se insere no debate entre ação $x$ estrutura no contexto das ciências sociais, no qual existiria uma dicotomia entre a tradição marxista, de um lado, e a tradição chayanoviana, de outro, esta mais próxima da tradiçãao neoclássica.

Francisco de Assis Costa defende que a sociologia ou a economia política de Marx oferece uma visão que destaca a dimensão macrossistêmica, importante para o entendimento do todo em interação com as suas partes. Porém, esse entendimento do todo finda produzindo reduções criticáveis, como o entendimento da agricultura e do campesinato na sociedade capitalista. Na visão marxista, politicamente, por exemplo, o camponês nunca iria exercer um papel transformador na sociedade, pois cada unidade familiar é uma unidade particular, diferentemente dos trabalhadores da indústria, que mais facilmente podem se identificar na condição de classe para si, ou seja, como um conjunto de pessoas que tem o mesmo interesse e que se organizam politicamente para colocá-lo na pauta da sociedade. Isso não acontecia com os camponeses que poderiam ser, no máximo, como saco de batatas, pois em determinados momentos eles podem até se unir, quando algo poderia ameaçar os seus interesses mais gerais, mas, quando o saco se rompesse, cada um iria para o seu lado, voltando à sua condição de isolamento.

Dessa forma, Marx também pensava numa especificidade da economia camponesa, que é o fato de o camponês "entregar de graça" parte de seu excedente para a sociedade. Isso acontecia devido ao grande poder de subsunção do capital mercantil. Por outro lado, se a taxa de lucro cai, ainda assim o camponês continua produzindo. Para Marx, por não ter uma atitude de empresário, o camponês não iria sobreviver por muito tempo dentro do contexto de concorrência. Desde Marx, portanto, que a gestão da agricultura sustentada por uma economia moral baseada na lógica familiar não é vista como algo compatível com o capitalismo, que traz consigo uma 
necessidade constante de inovar. Lênin teria incorporado essa perspectiva para o estudo do campesinato na Rússia, chegando aos mesmos resultados de Marx, assim como Kautsky na Alemanha.

Também na União Soviética vigorava a ideia de que os camponeses eram incapazes de incorporar as inovações tecnológicas no processo produtivo, o que não levaria ao desenvolvimento das forças produtivas, daí a destruição dos camponeses por Stálin podendo ser vista como as consequências da perspectiva marxista sobre o campesinato. No Brasil, nos anos de 1960, com o surgimento da figura do boia-fria, tal movimento acabou sendo interpretado pela sociologia e economia política brasileiras, nessa época, como um processo de proletarização dos trabalhadores rurais, processo esse que acabou sendo visto como sinônimo de eliminação dos camponeses. Defendiam essa perspectiva autores como Octávio Ianni, Maria Wanderley e José Graziano da Silva, por exemplo.

Nesse sentido, no Brasil, até bem pouco tempo atrás, partidos políticos e intelectuais defendiam essa ideia de extermínio dos camponeses como algo inevitável. O Estado brasileiro, por exemplo, agia como se o campesinato não existisse, refletindo na completa ausência, até poucas décadas atrás, de políticas de crédito, dentre outras, orientadas para os camponeses. José Eli da Veiga e Ricardo Abramovay, por sua vez, vão mostrar que os camponeses são importantes para o país e que a agricultura de base familiar existe por toda parte no mundo. A contribuição desses autores teria sido mostrar como a agricultura que se modernizou e se inovou, no caso de países como Inglaterra, França e Estados Unidos, foi em base camponesa e não patronal.

Se, por um lado, a teoria de Marx se revela de grande importância na explicação da lei do valor, por exemplo, os problemas surgem quando essa teoria busca explicar outras realidades nas quais nem todos os elementos da teoria da lei do valor estão presentes para que ela possa funcionar, como é o caso da economia camponesa. A análise de Chayanov representa um contraponto às interpretações marxistas, em primeiro lugar, por ressaltar que a variável salário não está presente na lógica camponesa, uma vez que o trabalho do camponês não entra na lógica produtiva na forma de trabalho as- salariado. E isso não é uma anomalia, mas uma forma diferente de gerir o processo de trabalho. Essa diferença, por seu turno, não resulta em incompatibilidades entre o campesinato e outros modos de produção, visto que formas camponesas conviveram com o escravismo romano, com o feudalismo, com o socialismo e com o capitalismo.

Chayanov teve a vantagem de viver e pesquisar no final do século XIX e início do século XX, observando que a economia camponesa continuava sobrevivendo junto com a economia capitalista em vários países da Europa. Isso o teria feito levar a sério o desafio de explicar a presença empiricamente demonstrada dos camponeses em vários países. Segundo o autor, a grande vantagem da teoria chayanoviana é a explicação do ponto de equilíbrio entre as condições internas da unidade de produção camponesa, o chamado equilíbrio chayanoviano. Esse equilíbrio pode variar apenas em função das condições internas da família, como o nascimento de mais um filho, por exemplo.

O legado de Chayanov estaria, portanto, na construção de uma visão de grande importância para o entendimento da especificidade camponesa, ainda que a sua abordagem se aproxime, em alguma medida, da tradição neoclássica, especialmente pela utilização do pressuposto do individualismo metodológico. Entretanto, tal abordagem se ressente de uma visão ou de um panorama mais geral, mais global, da economia camponesa.

Assim, esta é a lacuna, no campo teórico-metodológico, que a obra de Francisco de Assis Costa busca preencher: a construção de uma leitura que supere a dicotomia entre a tradição marxista, que destaca as determinaçôes do sistema envolvente, e a tradição chayanoviana, que realça as condições internas da unidade de produção camponesa. Para tanto, o autor propóe uma teoria alternativa e unificada da economia camponesa.

Nessa teoria, a noção de eficiência reprodutiva é central, pois explicita o essencial nas relaçôes entre as especificidades da razão camponesa e as leis gerais de reprodução capitalista. Uma vez que os camponeses se sintam ameaçados em seu processo de reprodução enquanto ser social, eles tendem a mudar, tomando decisões que garantam a sua reprodução social, entrando num processo muito 
intenso de inovações (investimento), não obstante parecer que eles estejam parados.

Dessa forma, a tensão reprodutiva provoca uma mobilização ou uma disposição a mudar, que tende a guardar uma relação estreita com uma mudança real, com um investimento de fato. No que parece ficar claro que o horizonte da mudança é algo inerentemente interiorizado na lógica camponesa, evidenciando que o camponês não é resistente às mudanças, porém ele não pode sucumbir a qualquer mudança, pois o que está em jogo é a eficiência reprodutiva da família enquanto unidade de produção. Os camponeses só não mudam quando suas condições de reprodução estão sendo plenamente atendidas ou quando as possibilidades de mudança são bloqueadas, como é o caso das mediações institucionais expressas nas políticas de crédito, de assistência técnica e de extensão rural, por exemplo. Não se trata, portanto, de um sistema estável, mas dinâmico, pois, na proporção em que a tensão reprodutiva se eleva, aumenta a propensão ou a mobilização ao investimento. É isso que o autor procura mostrar nos casos dos agricultores norte-americanos (capítulos 7 , 8 e 9) e dos municípios paraenses de Capitão Poço e Irituia (capítulos 11 e 12).

No caso dos Estados Unidos, por exemplo, a agricultura é predominantemente de base familiar. $\mathrm{O}$ crescimento em tamanho das unidades produtivas se dá por uma necessidade familiar e não por uma negação dessa base familiar. Neste ponto, é importante ter em mente a diferença entre forma e natureza, haja vista que algumas perspectivas de análise afirmam que, por terem encontrado formas camponesas diferentes, não se tratam mais de camponeses. Este é o caso dos camponeses norte-americanos, que, por terem atingido um elevado nível tecnológico no processo produtivo, alguns autores consideram que não se tratam mais de camponeses. A tese de Francisco de Assis Costa é a de que, entre os camponeses americanos, a essência, o fundamento chayanoviano ou a natureza de camponês de articulação entre as esferas da produção e do consumo, se faz presente.

Nesse ponto, o autor introduz o importante entendimento de que o agrário sendo dominado pelas grandes propriedades, com os grandes latifúndios comandando o processo de modernização da agricultura, é uma realidade peculiar ao Brasil, pois, em outros países onde isso acontecia, reformas foram feitas no sentido de impedir esse domínio dos grandes latifúndios. Assim, países ditos desenvolvidos, como os Estados Unidos, possuem agricultura fundamentalmente de base camponesa, diferentemente do Brasil, onde o grande latifúndio é que está à frente do processo de modernização da agricultura.

Também no caso amazônico, a presença camponesa não pode ser vista como um dado irrelevante. É o que evidencia o caso dos camponeses dos municípios paraenses de Capitão Poço e Irituia. Em Capitão Poço, por exemplo, o autor mostrou que a lógica de investimento se fez por meio da transição de culturas temporárias para sistemas mais complexos, de maior diferenciação produtiva, reduzindo os riscos e aumentando a capacidade de assimilar renda média por trabalhador. Tal resultado aponta, mais uma vez, para a importância da mobilização ao investimento entre as estruturas sociais camponesas.

Francisco de Assis Costa destaca ainda a centralidade do elemento camponês ou da realidade camponesa para a compreensão da realidade agrária amazônica. Aqui, o autor contribui para desconstruir abordagens que colocam a Amazônia apenas como uma extensão da agricultura ou da fronteira agrícola no Brasil. Ou, ainda, aquelas perspectivas de análise que tratam as estruturas sociais camponesas amazônicas como uma realidade invisível, como uma economia miserável ou até mesmo ausência de economia. Na visão do autor, essas abordagens são equivocadas, pois deixam de considerar e discutir o que é mais fundamental no processo de desenvolvimento histórico da região, que é a presença das estruturas camponesas. Trata-se de uma importante valorização dos camponeses como atores econômicos e políticos para uma estratégia de desenvolvimento sustentável.

Ao final, a principal mensagem do autor para o entendimento da realidade amazônica parece residir no fato de que os camponeses devem ser considerados atores capazes de ser protagonistas de um processo de desenvolvimento que se quer em bases sustentáveis, ecológica, econômica e socialmente. Nas palavras do próprio autor, “o Brasil será um 
país equânime, no sentido da qualidade de vida das grandes massas e do seu acesso aos bens públicos, na razão direta do sucesso dos camponeses em criarem ou aproveitarem oportunidades para ampliar e fortalecer, econômica e politicamente, sua presença na sociedade" (p. 298).

Por fim, ressalto que a leitura do livro é altamente recomendável para todos os que se dedicam ao estudo das sociedades rurais, iniciados ou não nos aspectos teóricos, empíricos e metodológicos que envolvem as questóes ligadas ao campesinato na Amazônia, no Brasil e no mundo. Trata-se de obra relevante, teoricamente densa e metodologicamente inovadora, de significativa contribuição para as ciências sociais no Brasil.

LUIZ CLÁUDIO MOREIRA MELO JÚNIOR é professor assistente da Universidade Federal Rural da Amazônia e doutorando em desenvolvimento sustentável pelo Centro de Desenvolvimento Sustentável da Universidade de Brasília (CDS/UnB). E-mail: luiz.mmelo@hotmail.com.

DOI: http//dx.doi.org/10.17666/3089186-190/2015 